\title{
Whiskey webs: Microscale "fingerprints" of bourbon whiskey
}

\author{
Stuart J. Williams, " Martin J. Brown, VI, and Adam D. Carrithers \\ Department of Mechanical Engineering, University of Louisville, Louisville, Kentucky 40292, USA
}

(Received 20 January 2019; published 24 October 2019)

\begin{abstract}
This paper is associated with a poster winner of a 2018 APS/DFD Milton van Dyke Award for work presented at the DFD Gallery of Fluid Motion. The original poster is available online at the Gallery of Fluid Motion, https://doi.org/10.1103/APS.DFD.2018. GFM.P0002
\end{abstract}

DOI: 10.1103/PhysRevFluids.4.100511

When a drop of liquid that contains colloids is evaporated, the suspended particles can deposit on the surface in a "coffee-ring" pattern [1]. A variety of techniques exist to manipulate the deposition and assembly of these micro- and nanoparticles. One unique example [2] demonstrated that the inherent chemical properties of a Scotch whiskey (Glenlivet, UK) enabled a uniform deposition of colloids. We were curious if American whiskeys behaved similarly; a distinct characteristic of American whiskey (excluding corn whiskey) is that it is aged in charred new oak containers. Whiskeys that mature in such containers extract more water-insoluble contents compared to those matured in uncharred barrels for the same amount of time [3]. Figure 1 shows that a uniform film is generated by American whiskey with an alcohol-by-volume (ABV) greater than $35 \%$ and that coffee-ring patterns developed for low ABV (10\%). However, an unexpected weblike structure formed at intermediate ABV (20\%).

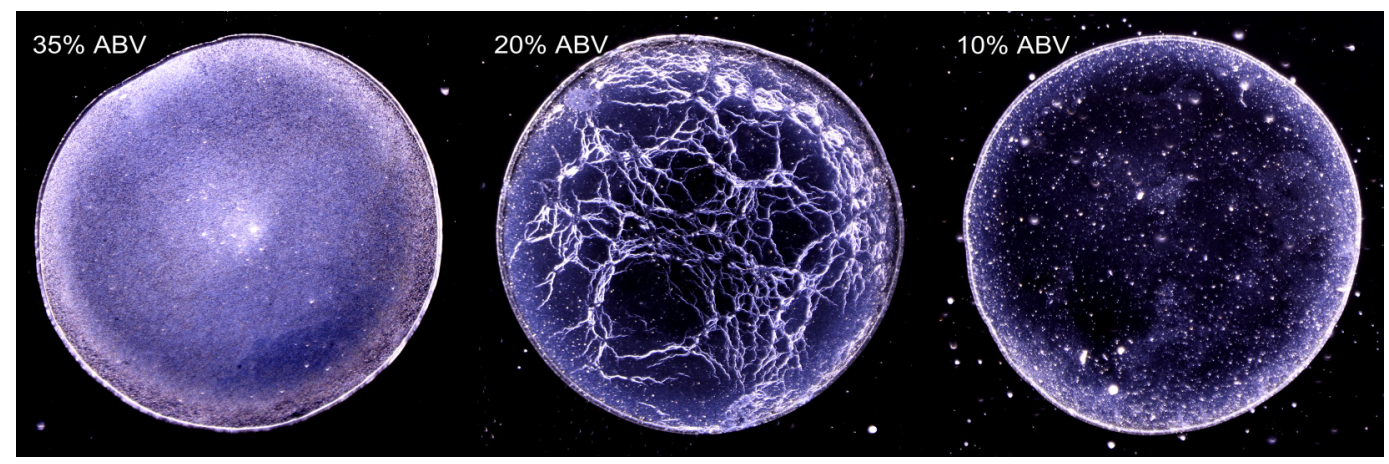

FIG. 1. The resulting evaporation patterns associated with evaporating a drop of diluted Rabbit Hole ${ }^{\mathrm{TM}}$ bourbon whiskey. The poster associated with this image is available at https://doi.org/10.1103/APS.DFD.2018. GFM.P0002

\footnotetext{
*stuart.williams@louisville.edu
}

Published by the American Physical Society under the terms of the Creative Commons Attribution 4.0 International license. Further distribution of this work must maintain attribution to the author(s) and the published article's title, journal citation, and DOI. 


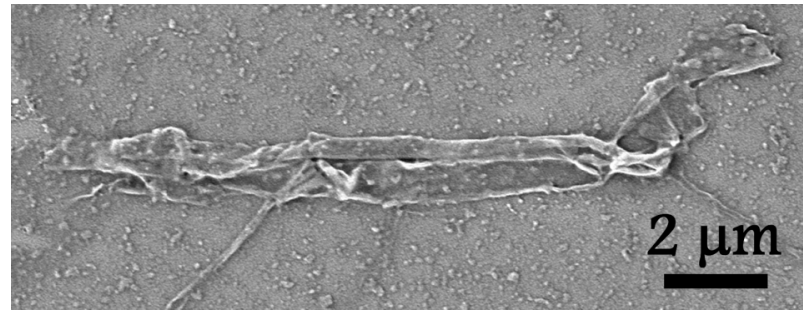

FIG. 2. SEM image of a single web structure (coated with a thin layer of gold to enhance image features). The poster associated with this image is available at https://doi.org/10.1103/APS.DFD.2018.GFM.P0002

These patterns were created by depositing a $1.0 \mu \mathrm{L}$ droplet on an acetone-cleaned glass coverslip with evaporation occurring at ambient conditions. Each image was approximately $2 \mathrm{~mm}$ in diameter and was imaged using an inverted microscope, back-illuminated with scattered light from a LED ring light.

Fluid flow observations were consistent with previous work $[2,4]$ in that the first phase of evaporation $(<1 \mathrm{~min})$ generates relatively significant turbulent motion before transitioning to laminar, radially circulating flow. The turbulent phase plays an important role in the final selfassembled web pattern. Micelles are initially formed when whiskey is diluted with water. These micelles reach the air-liquid interface and form monolayers, which are thereafter disrupted during the evaporation-induced turbulence. Figure 2 shows a scanning electron microscope image of the final structure, which resembles a collapsed monolayer [5].

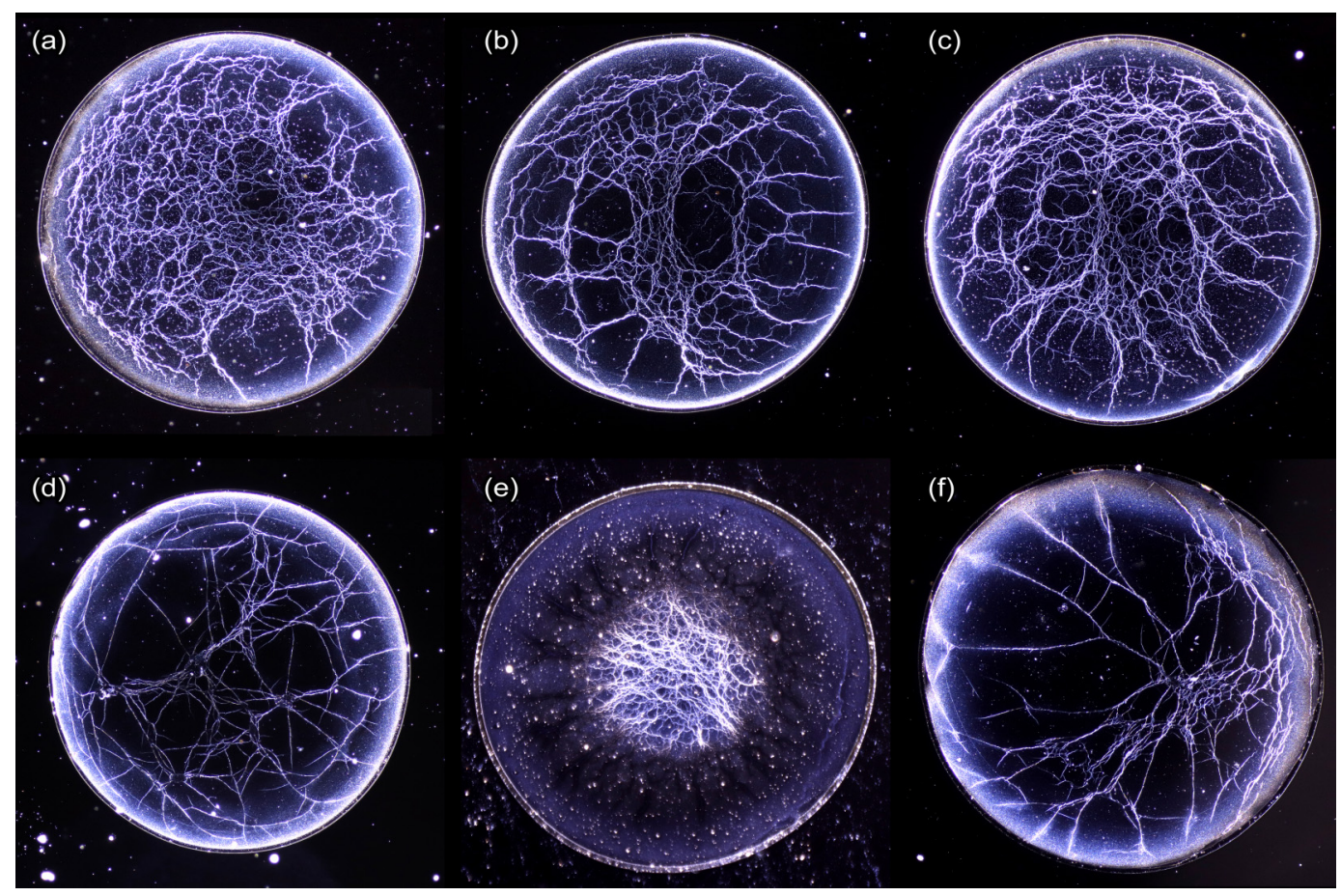

FIG. 3. The resulting whiskey web patterns are unique to each sample of tested American whiskey. These images include diluted samples from (a) Four Roses ${ }^{\mathrm{TM}}$ at $22.5 \% \mathrm{ABV}$, (b) Heaven Hill ${ }^{\mathrm{TM}}$ at $22.5 \% \mathrm{ABV}$, (c) Maker's Mark Cask Strength ${ }^{\mathrm{TM}}$ at $22.5 \%$ ABV, (d) Jack Daniel's Single Barrel Barrel Proof ${ }^{\mathrm{TM}}$ at $25 \%$ ABV, (e) Pappy Van Winkle's Family Reserve 23 Year $^{\mathrm{TM}}$ at $25 \% \mathrm{ABV}$, and (f) Woodford Reserve Double Oak ${ }^{\mathrm{TM}}$ at $25 \%$ ABV. The poster associated with this image is available at https://doi.org/10.1103/APS.DFD.2018.GFM.P0002 
This self-assembly mechanism is a function of extrinsic properties (temperature, humidity, etc.) and key whiskey intrinsic properties, the latter demonstrated by the unique patterns created by different American whiskey products (Fig. 3). Whiskey webs formed for a variety of American whiskeys, but not for distillates $(n=5)$, indicating that the charred new oak barrel and maturation conditions play a significant role. As such, this technique could be used to differentiate American whiskeys from counterfeits as well as provide insight into product maturation.

[1] W. Han and Z. Lin, Learning from "coffee rings": ordered structures enabled by controlled evaporative self-assembly, Angewandt. Chem. Int. Ed. 51, 1534 (2012).

[2] H. Kim, F. Boulogne, E. Um, I. Jacobi, E. Button, and H. A. Stone, Controlled Uniform Coating From the Interplay of Marangoni Flows and Surface-Adsorbed Macromolecules, Phys. Rev. Lett. 116, 124501 (2016).

[3] C. A. Crampton and L. M. Tolman, A study of the changes taking place in whiskey stored in wood, J. Am. Chem. Soc. 30, 98 (1908).

[4] J. R. E. Christy, Y. Hamamoto, and K. Sefiane, Flow Transition within an Evaporating Binary Mixture Sessile Drop, Phys. Rev. Lett. 106, 205701 (2011).

[5] H. E. Ries and H. Swift, Twisted double-layer ribbons and the mechanism for monolayer collapse, Langmuir 3, 853 (1987). 